\title{
COMIDAS E COZINHA NA CULTURA SERTANEJA: PASSADO E PRESENTE NO INTERIOR DA BAHIA
}

\author{
Raimundo Pinheiro Venâncio Filho ${ }^{1}$
}

\begin{abstract}
Resumo: o presente artigo busca analisar as comidas e cozinha sertaneja da Bahia condicionadas as condições climáticas ao longo do tempo. O estudo revela os valores do sertão baiano, mostrando as particularidades culturais e o que é produzido regionalmente, como os ingredientes da culinária, que fazem parte dos princípios de participação comunitária e sustentabilidade dos municípios. A relação da culinária do sertão e sua adaptação às condições climáticas evidenciou a importância de se mostrar como os sertanejos, - apesar das condições climáticas adversas, a falta de água e a impossibilidade de produção agropecuária ampla e contínua -, indicam estratégias de sobrevivência em condições adversas, ao tempo em que se apontam pratos exóticos e de sabor realçado, ao gosto sertanejo, onde a forma de se alimentar associada às condições climáticas, podem permitir, também, através da comida, marcar a sua identidade.
\end{abstract}

Palavras-chave: Sertão baiano, secas, comidas.

\section{SERTANEJA FOOD AND KITCHEN: PAST AND PRESENT IN BAHIA}

\begin{abstract}
The present article seeks to analyze the food and cuisine of the country of Bahia conditioned to climatic conditions over time. The study reveals the values of the Bahian hinterland, showing the cultural particularities and what is produced regionally, as the culinary ingredients, which are part of the principles of community participation and sustainability of the municipalities. The relationship between the sertão's cuisine and its adaptation to the climatic conditions showed the importance of showing how the sertanejos, - despite the adverse weather conditions, the lack of water and the impossibility of wide and continuous agricultural production -, indicate strategies of survival under conditions. adverse effects, at the same time as exotic dishes with an enhanced flavor, are the taste of the country, where the form of food associated with climatic conditions can also allow, through food, to mark their identity.
\end{abstract}

Keywords: Bahian hinterland, dried, food.

\section{COMIDA Y COCINA EN LA CULTURA SERTANEJA: PASADO Y PRESENTE DENTRO DE BAHIA}

Resumen: el presente artículo busca analizar la comida y la cocina de Bahía condicionadas a las condiciones climáticas a lo largo del tiempo. El estudio revela los valores del interior de Bahía, mostrando las particularidades culturales y lo que se produce regionalmente, como los

\footnotetext{
${ }^{1}$ Doutor em Planejamento Territorial e Desenvolvimento Social, pela Universidade Federal da Bahia. Docente na Faculdade do Sertão Baiano. Pesquisador na Universidade Católica de Salvador e Coordenador do Projeto Educação Patrimonial Conhecendo o Meu Lugar, pelo CNPq. E-mail: raigeografia@ hotmail.com.
} 
ingredientes de la cocina, que son parte de los principios de participación comunitaria y sostenibilidad de los municipios. La relación entre la cocina del sertão y su adaptación a las condiciones climáticas mostró la importancia de mostrar cómo las personas del interior del país, a pesar de las condiciones climáticas adversas, la falta de agua y la imposibilidad de una producción agrícola extensa y continua, indican estrategias para la supervivencia en condiciones adversas, en el momento en que se señalan platos de sabor exótico y mejorado, al sabor de los bosques, donde la forma de comer asociada con las condiciones climáticas, también puede permitir, a través de los alimentos, marcar su identidad.

Palabras clave: sertão bahiano, sequías, comidas.

\section{Introdução}

Para compreender as comidas do sertão é necessário conhecer a cozinha brasileira. Esta cozinha, sofrendo influências da cozinha portuguesa, juntamente com a indígena e a africana, promoveu inúmeras variações. Dessa forma, a alimentação sempre esteve relacionada à história dos diferentes povos e, para descrever e entendê-la, é preciso retornar ao passado e avançar até se chegar ao período atual.

Dos índios, se herdou o gosto por comidas à base de mandioca e milho, alimentos cozidos ou assados na folha de bananeira, a canjica nordestina, (curau de milho amarelo), a pamonha e a paçoca (TEMPASS, 2005, p. 15). As carnes, de acordo com Fernandes (2000, p.22) mesmo sendo um alimento secundário para os índios, eram variadas, como a carne de macaco, antas, peixes, lagartos, cobras e a do porco-do-mato, sendo esta última a mais abundante. Este mesmo autor afirmou que o modo como se explora ingredientes na cozinha, formas de preparar, dosar, confeccionar, temperar e conservar os alimentos foram herdados dos portugueses. Os lusos, desde o período colonial, trouxeram, ainda, os hábitos alimentares, os utensílios, as horas de refeição, as ordens dos pratos, os pesos e as medidas, ou seja, a proporção dos alimentos. Oliveira (2011) complementou ainda dizendo que, a comida brasileira, na relação da culinária com os costumes africanos, incorporou ingredientes que deram origem a outros pratos, somando-se ao que já se usava no Brasil.

Quando se utiliza a expressão "comida regional” se está referindo àquela, na qual os ingredientes são produzidos num território específico. A comida da "terra", nesse caso, está associada a alguns gêneros alimentícios, como a "batata da terra" e "frango da terra", conhecidos também como "batata--doce" e "galinha caipira" respectivamente. A despeito disso, Canesqui e Garcia (2005, p.9) afirmaram, ainda, que a comida compreende seleções, ocasiões 
e mesmo rituais, que possuem significados e experiências. "Para serem comidos ou comestíveis, os alimentos precisam ser elegíveis, preferidos, selecionados e preparados ou processados pela culinária, e tudo isso é matéria cultural".

As comidas do sertão baiano são menos conhecidas no litoral, mas muito tradicionais nos hábitos alimentares das cidades do interior, onde mesmo simples, é de base nutritiva e saborosa dos seus habitantes. Bolos, doces, biscoitos, papas e mingaus, rapadura e mel, milho, tapioca e cuscuz, feijão, caças, galinha, carnes, peixes, farofas, verduras e legumes como maxixe e abóbora, dentre outros produtos, fazem parte da gastronomia sertaneja. Ultimamente, espécies vegetais, tradicionalmente utilizadas, exclusivamente, para ração animal ou consumida por humanos, durante o período das secas rigorosas, - a exemplo da palma e mandacarú -, foram incorporadas ao menu de restaurantes regionais como um novo prato.

Suassuna, autora de "Gastronomia sertaneja: receitas que contam histórias" (2010), acredita que, a falta de divulgação das comidas da caatinga é a razão que as fazem pouco conhecidas. Afirmou que a escassez de alimentos, no sertão, fez com que as pessoas valorizassem o que se cultivava e produzia nele.

A chuva sempre marca um dos acontecimentos mais importantes no sertão. É ela que nivela a produtividade da matéria prima empregada nas comidas. A esse respeito, portanto, deve ser levada em consideração a sazonalidade, que dá ritmo à vida sertaneja, incluindo os alimentos e sua utilização nas cozinhas. O milho, por exemplo, se destaca em épocas de boa colheita, sem secas, servindo para fazer diversas iguarias, como pamonha, canjica e mingau, não exclusivas do Nordeste e do sertão baiano, mas que obedecem à sazonalidade para utilizar matéria prima local, não industrializada.

A ingestão de alimentos no sertão, sempre esteve ligada, sobretudo, à sobrevivência. As particularidades da comida sertaneja revelam os costumes, o modo de pensar e de viver dos habitantes das diversas localidades, muito embora haja certa homogeneidade alimentar em todo território do sertão da Bahia. Esses habitantes conceberam o ato de se alimentar, de maneira própria, ao longo de suas vidas, - quando e onde o clima é que sempre influenciou os valores, crenças -, bem como a cultura geral classificada como popular. Ao se referirem, a esse assunto, Assis et al., (1999, p. 160) constataram que, a necessidade de manter o corpo forte está associada às expressões dessa cultura, como "comida de pobre, comida leve e comida carregada".

A culinária identificada no sertão baiano, envolve ingredientes e matérias primas que se relacionam com o bioma da caatinga, se destacando os diversos doces, que são pontuais e 
aliados às condições da natureza. Entre eles, são utilizadas frutas nativas ou cultivadas na região, a exemplo do umbu e do licuri. O milho, que é bastante plantado nas roças, também é matéria-prima de muitas receitas, se equiparando ao bode, cuja criação é preponderante na região.

O presente trabalho tem como objetivo, identificar, localizar e contextualizar os costumes sertanejos ligados ao clima regional, revelando as heranças e tradições associadas à culinária, que envolve modos de preparos, matérias-primas regionais, crenças, tradições e as receitas criadas ao longo da história, exibindo os resultados desse processo que são as comidas do sertão baiano. Utilizou-se a metodologia mais recorrente de análise e síntese, utilizando técnicas de procedimento, como consultas bibliográficas, documentais, coadjuvadas por pesquisa de campo, - com uso de entrevistas abertas e observações pessoais buscando mostrar de forma qualitativa, a culinária do sertão baiano.

\section{Cozinha sertaneja}

O escritor Euclides da Cunha já tinha apontado nos inícios do século XX que, mesmo em tempos normais, o sertanejo comia de forma muito básica, bastando-lhe alguns punhados de farinha com rapadura para atravessar os dias. Apontou que, em Canudos, antes dos conflitos, um capuchinho que pregava na vila, falava sobre as virtudes de um jejum que devia ser praticado, porém de forma moderada. Quando explicava o que seria um jejum moderado, provocava risos entre os presentes que classificavam aquilo como uma refeição farta. $\mathrm{O}$ autor não escreveu sobre as experiências culinárias, - dele ou dos sertanejos -, em sua obra, mas fez referência ao prazer destes últimos "desalterando-se com a umbuzada saborosíssima, ou merendando a iguaria incomparável do jerimum com leite" (CUNHA, 1963, p. 57).

As comidas do sertão, possuindo características próprias, como já tinha indicado Mascarenhas (2007, p. 65), devem ser analisadas pela sua variedade, fruto da sua heterogeneidade cultural e diversidade, com sabores específicos, que expressam o cotidiano regional, a sua memória e o passado. As comidas do sertão estão associadas à cultura popular e compreendidas como fruto de interação das relações sociais (GARCIA CANCLINI, 1995, p. 45). O alimento, utilizado para saciar a fome, é modelado pela cultura de cada região. No sertão baiano, essa modelagem foi, nitidamente, influenciada pelo clima, que sempre produziu efeitos na organização socioeconômica da população como um todo, com características bem próprias.

Elas não se reduzem aos pratos mais tradicionais ou ingredientes específicos. Maciel e Garcia, - nos seus estudos sobre identidade cultural e alimentação -, classificaram a comida como uma forma de linguagem, envolvendo as identidades dos grupos que a produzem. 
Destacaram que "o prato serve para nutrir o corpo, mas também sinaliza um pertencimento, servido como um código de reconhecimento social” (MACIEL; GARCIA, 2005, p. 52).

A cozinha sertaneja tem a marca da cultura regional. Por trás dos pratos típicos, existem histórias, tradições, formas próprias de preparo, além de ingredientes, que estão associados ao meio social e natural, o que proporciona uma comida singular, que representa mais que simples alimentação. No sertão baiano, as tradições enraizadas, representam a identidade dessa porção do Estado. Essas tradições e hábitos estimularam um novo mercado consumidor no litoral, onde produtos diferentes, envolvendo matérias-primas e modos de fazer distintos dos costumes desses consumidores, simbolizam e oferecem a oportunidade de descobrir, ou mesmo reviver práticas culturais alimentares.

Os estudos de Amon e Maldavsky (2012, p. 20), que abordaram a comida como narrativa social, se voltaram para o sertão baiano no que diz respeito às crenças e formas simbólicas associadas ao cotidiano dos moradores da região. Os autores afirmaram que as relações sociais nesses lugares tendiam a ser mais estáveis porque as pessoas compreendiam umas às outras. A apropriação das práticas e saberes desses moradores pode adquirir novas características de acordo com os objetivos que os levam a criar atitudes, o que pode ser identificado, por exemplo, nos pratos da cozinha sertaneja oferecidos em restaurantes que utilizam o discurso de comida forte e diferente.

À medida que crescia a ocupação do sertão, a influência da cozinha portuguesa foi se adaptando ao novo território, conforme afirmou Radel (2002, p. 19). Os refogados, ensopados, guisados e assados, - típicos dos portugueses -, eram preparados no sertão, com bodes, carneiros e caças e, ainda, se associando ao angu, pirão e farinha de mandioca.

Ainda sobre a dimensão cultural da alimentação, Canesqui e Garcia (2005, p. 25) enfocaram as crenças e proibições associadas às comidas. No sertão, o período de "resguardo" após o parto, obedece uma alimentação rigorosa para garantir a saúde da mãe e a qualidade do leite para a criança. É o exemplo do mingau ou pirão de parida, - feito com farinha e galinha caipira -, indicado como o ideal para essa fase de recuperação.

Corner e Angelo (2008), tratando do patrimônio cultural imaterial, apontaram que na gastronomia pode ser encontrada a herança de uma geração passada que se revela na atual. Os gostos e os costumes possuem uma mesma origem, uma mesma linguagem. Usados continuadamente no tempo e no espaço, marcam uma das principais características de um ou mais grupos sociais, conferindo-lhes identidade cultural. Por isso mesmo, como Poulain (2013) 
afirmou, a patrimonialização do alimento e da gastronomia está associada ao receio da perda de identidade local.

Diversos utensílios são utilizados para fazer a comida sertaneja, a exemplo da urupemba - peneira de palha, de origem indígena feita de palha da palmeira do licuri -, a legra, - usada no sertão como raspador de queijo e milho -, a chaleira de zinco, que serve para esquentar água e o pilão, para socar o milho, o licuri, a carne seca e o café. Além destes, as frigideiras e panelas diversas como a de pressão, são usadas na cozinha sertaneja, assim como a colher de pau e os tachos de zinco e de ferro mais usados para fazer doces.

Muitas cozinheiras nessa região, trabalham com o fogão a lenha construídos nas cozinhas, alguns improvisadamente instalados no chão, como forma de minimizar gastos. Outras cozinheiras tem aparelhos mais organizados, como no caso de restaurantes, que recorrem ao gás de cozinha.

A identidade da comida sertaneja está ligada à disponibilidade de recursos do meio onde os ingredientes são cultivados. O sertanejo definiu, ao longo de sua vida, o que é ou não é comida, o que é permitido ou adequado ou inadequado para o seu gosto. Considerando a variedade de espécies de comidas encontrada na cozinha sertaneja, se identifica que os gostos foram se somando de acordo com o decorrer da história da ocupação do território, das condições socioeconômicas, da cultura compartilhada, do bioma natural ou domesticado, de gêneros comestíveis e, no caso em especial o clima. Dessa forma, se construiu a culinária antiga e atual do sertão baiano.

A ausência quase que completa de verduras e frutos no cardápio sertanejo é uma característica marcante nos hábitos e costumes dessa região. Às vezes é usado um tomate cortado em pequenos pedaços, coentro, cebola para acompanhar a carne. Esta, por sua vez é muito apreciada, principalmente a de bode e carneiro. Assada ou guisada, é a carne preferida dos sertanejos. A carne do sol, oriunda do modo de preparar a carne do boi, também faz parte da preferência dos sertanejos, assim como os diversos tipos de doces.

Quem nasceu no sertão aprendeu a conviver com fatores que em muitas ocasiões gerava dificuldades, como a fome. Nesses episódios ligados principalmente às épocas de secas, à inovação na maneira de se alimentar fez com que se aproveitasse tudo que se tinha à disposição para a sobrevivência, sendo esses os motivos da cozinha sertaneja variada. As constantes estiagens ao longo do tempo, fizeram com que os sertanejos aproveitassem o que o bioma que os cercava oferecia para sua sobrevivência, além do que ainda se podia cultivar como mandioca, abóbora, batata-doce, milho e feijão. Apoiada na herança indígena e influenciada 
Fronteiras: Revista de História

Comidas e cozinha na cultura sertaneja: passado e presente no interior da Bahía

Raimundo Pinheiro Venâncio Filho

pela cozinha portuguesa, a cozinha sertaneja como se vem apontando, surgiu condicionada pelo clima semiárido e a integração do homem ao mesmo.

\section{Alimentos da fome no sertão}

A fome no sertão foi por muito tempo um dos principais temas discutidos em diversas obras literárias ou relatos de cronistas e viajantes nacionais ou estrangeiros. As secas que assolaram o Nordeste contribuíram para que fossem dadas a conhecer as mazelas, a miséria e a escassez de alimentos. Alguns autores trataram do tema com uma visão hostil sobre a região das caatingas, onde a vida humana era ditada pelo ambiente natural.

Os viajantes Spix e Martius, em passagem por Monte Santo no sertão baiano no ano de 1818, escreveram sobre um desses períodos de estiagem, classificando-o como tempo de penúria. Descrevendo o licuri, palmeira presente na caatinga, fizeram referência ao uso do miolo do seu caule chamado bró, para o preparo da massa que servia para fazer um tipo de cuscuz para matar a fome. Referindo-se ao drama das secas, escreveram:

Precisar o povo de um país de riqueza tão exuberante recorrer a tais expedientes, para subsistir, nos parecia incrível, se não houvéssemos visto a miséria em que geralmente vive a gente nessa região do sertão, e se acha bem (SPIX; MARTIUS, 1976, p. 129).

O termo bró deriva de "broca", dado ao orifício grande que se faz no caule do licurizeiro quando retirada a massa do miolo. Apresenta uma cor roxa, cheiro forte e sabor amargo. Observando os animais se alimentando com essa massa, descobriu-se ser comestível e, assim, o sertanejo passou a adotá-lo como o último alimento quando não tinha mais nada para comer (SPIX; MARTIUS, 1976, p. 134).

Dentre vários espécimes existentes na caatinga, um dos mais importantes para os sertanejos foi e continua sendo o licuri, cujo caule como foi descrito, era utilizado por boa parte da população como o último recurso alimentar diante das secas. Agricultores do sertão relembram como era o processo para retirar o bró. Se derrubava o licurizeiro, descascava o caule e o levava para bater nos lajedos em cima de uma esteira. Nesse processo, ia se desprendendo uma massa, que era torrada e transformada em farinha para com ela serem feitos beiju ou cuscuz. A massa era colocada em um pilão para ser pisada. Após esse processo, se peneirava e fazia o cuscuz ou o beiju. Servia também para preparar um mingau para as crianças. 
Os umbuzeiros, utilizados também como comida da fome quase desapareceram durante as grandes secas. Praticamente todos os tubérculos encontrados nas raízes da planta do umbuzeiro eram retiradas para se comer junto com algum cozido, o que provocou o extermínio da espécie na região.

Ao se referir sobre o assunto, Euclides da Cunha fez a descrição de alguns alimentos utilizados pelos sertanejos durante os períodos de seca. Afirmou que na região de Canudos a seca era inevitável, detalhando o cenário do sertão baiano com bois magros e famintos e a população se alimentando do bró, classificado como "um pão sinistro que incha os ventres, empanzinando os famintos" (CUNHA, 1963, p.56). Deu notícias, ainda, sobre o uso das raízes dos umbuzeiros e dos cactos, como fonte de alimento e de água para beber.

Além de Euclides da Cunha, outros autores importantes trataram do tema sobre a fome, inspirados nas cenas dramáticas da vida dos sertanejos. Rodolfo Teófilo (2002), baiano, - que morou no Ceará -, introduziu a literatura regional naturalista no Nordeste e foi um dos precursores a tratar do mesmo tema. Médico, poeta e cronista, foi o autor do romance publicado em 1890 que falava dos horrores das secas e migrações cearenses, denunciando o flagelo em "A fome". Em “A bagaceira" de José Américo de Almeida (1980, p.72), inaugurou junto com Macunaima de Mário de Andrade em 1928, o romance nacionalista e/ou regionalista. O personagem principal, João Troculho, falava que o seu maior desejo era "comer até matar a vontade”. Raquel de Queiroz (2004) em “O quinze”, no seu primeiro romance de 1930, mostrou um personagem comendo uma cabra que encontrou no caminho já morta pela grande seca de 1915.

No romance "Vidas secas" de Graciliano Ramos (2007) escrito em 1938, publicado no ano seguinte com ilustrações de Aldemir Martins, retratou a cachorra Baleia sonhando com um mundo cheio de preás gordos para comer e descreveu personagens vivendo na crueza da seca. A maior parte dessas obras inspiraram o pintor paulista, Candido Portinari a retratar esses personagens que migravam do Nordeste para São Paulo.

Plantas da caatinga foram utilizadas como alimento ao longo das grandes estiagens. $\mathrm{O}$ pão de macambira, uma bromélia existente na caatinga, era feito a partir de uma espécie de batata transformada em farinha de mingau, farofa, angu ou biscoito. O pirão amargo da farinha feita da semente de mucunã, e as hastes novas do xique-xique assadas, - utilizadas também para alimentar o gado -, foram e são alguns "alimentos do desespero ou comida braba que atendia ao apelo famélico", como foram classificados por Cascudo (1983, p. 167). 
Esclarecendo mais as nuances do semiárido e sua influência sobre as secas e as comidas do sertão, Suassuna (2010, p. 8) afirmou que se pode estabelecer distinção entre as comidas de inverno, de estiagem e de seca. Durante a escassez de comida um prato muito utilizado entre as famílias no sertão é o "cabeça de galo" ou "pirão de ovos" feito do caldo de galinha que leva tomate, coentro, alho, pimentão, cebola, pimenta do reino, farinha de mandioca e ovos, um misto de sopa e de pirão ralo. Durante as secas, pela falta de ingredientes, era chamado de "caldo da fome" ou "mingau de cachorro", utilizando um único ovo para alimentar várias pessoas (SUASSUNA, 2010, p. 9).

Depoimentos de moradores idosos do sertão baiano destacaram, além dos episódios das grandes secas, as dificuldades alimentares e as novas estratégias de sobrevivência alimentar que presenciaram em suas vidas.

A mucunã, uma semente da caatinga, foi incorporada ao conjunto de saberes populares ligados à convivência com a natureza. Considerada venenosa, a mucunã serviu de alimento para os sertanejos, que aprenderam a retirar a sua toxidade lavando a semente em nove águas por nove dias. Após esse período as sementes eram pisadas, transformadas em farinha, misturada com licuri também pisado para se preparar o cuscuz.

Outra preparação própria da época das secas de que se tem notícia é o caxixe, uma bebida a base de suco de umbu cozido adicionado ao leite do coco de licuri pisado no pilão e acrescido de açúcar. Essa bebida de sabor adocicado tanto era utilizada em época de seca como, também, continua presente no cotidiano dos moradores na época da safra do fruto. Os sertanejos consideram o caxixe como "comida" forte, principalmente quando misturado à farinha, como costumam consumir.

Um alimento curioso do sertão baiano que existia nos períodos de estiagem era a chamada farinha de bode. Nessas épocas, quando a farinha também ficava escassa e se matava algum bode, - as vezes o que ainda restava vivo -, secava algumas partes menos nobres de sua carne e pilava até obter a farinha de bode.

As informações sobre as comidas da fome do sertão, assim como da cozinha sertaneja como um todo foram dadas na sua maioria por mulheres que se disponibilizaram a detalhar as estratégias alimentares de sobrevivência em diversos períodos de suas vidas. Se concluiu, que, no sertão, são as mulheres as responsáveis pela conservação das tradições de elaborar e preparar os alimentos. 


\section{Pratos típicos}

A comida sertaneja pode ser encontrada em diversos lugares, desde pratos simples como os de feiras livres, aos sofisticados preparados em restaurantes mais organizados. Dessa forma, a comida é importante tanto para saciar a fome do sertanejo mais simples, quanto para encantar o consumidor que quer algo diferente para degustar nos restaurantes.

Um exemplo de ingrediente que se incorporou à chamada gastronomia sertaneja é a palma forrageira, um tipo de cactácea. Nos restaurantes, mais recentemente, é utilizada para preparar diversos pratos a exemplo da torta e ensopado com carne seca.

As comidas sertanejas vêm sofrendo muitas mudanças devido à sua apropriação pela gastronomia industrial e comercial cujo preparo e os ingredientes buscam atrair um público específico, principalmente aqueles que procuram por algo novo no alimento. Alguns pratos passaram por alterações nos quais novos ingredientes, temperos e mesmo formas de preparo, buscaram desvincular de seu território ou de seus costumes tradicionais essa culinária que surgiu das dificuldades dos tempos das secas.

Hoje, mesmo com a apropriação dessa culinária pela gastronomia comercial e de produtos industrializados com a "evolução" de muitos pratos, o sabor original é conservado e os costumes tradicionais, - herdados dos mais velhos -, ainda predominam, fazendo com que as comidas do sertão continuem a fazer parte do sentimento de pertencimento de muitas pessoas.

Cascudo (1983, p.128), dizia que a cozinha sertaneja genuína é aquela criada pelos descendentes de índios. Tinha que ser uma comida de "sustança", afirmava o autor. Os pratos, em função da "sustança", são fortes e hoje classificados como comida pesada. A buchada de bode foi destacada pelo autor (CASCUDO, 1983, p.135) apontando que esse prato é composto pelo estômago do animal, recheado com as suas próprias vísceras temperadas. No município de Uauá no sertão baiano, por exemplo, a buchada de bode é um prato muito requisitado, acompanhado de farinha de mandioca que é tão importante para o sertanejo quanto o pão de farinha de trigo é para algumas regiões do País.

O bode e o carneiro se tornaram pratos tradicionais em todo o sertão da Bahia. Mesmo nos períodos mais difíceis como os de seca, a alta resistência dos animais da espécie possibilita o consumo dos diversos pratos preparados com esse tipo de carne. O sabor diferenciado da carne do bode dessa região está associado à vegetação da caatinga que alimenta os animais. As condições climáticas do sertão tornaram os animais rústicos, - mas que não perdeu a qualidade do sabor agradável (o bode era malcheiroso) -, bastante característico, diferente do observado 
em qualquer outro tipo de animal do mesmo tipo, criado em outro ambiente. "É, portanto, uma carne construída ao longo de quase 500 anos" (GUIMARÃES FILHO; LOPES; SILVA, 2014, p.118).

Plantas nativas da caatinga também são utilizadas na cozinha sertaneja. O mamão-deveado, por exemplo, é um arbusto resistente às secas. Muitas doceiras utilizam seus tubérculos para fazer o conhecido doce de mamão de veado encontrado nas feiras livres dos municípios do sertão baiano.

Essa comida influenciou a mesa do brasileiro, como o baião-de-dois, a carne-de-sol, a paçoca, a manteiga de garrafa, o queijo de manteiga e, especial a tapioca que, mais recentemente se tornou moda em todos os Estados e alcançando a Europa e o Oriente.

Exemplo de prato apreciado da cozinha sertaneja é o que tem por base a galinha, que foi introduzida no Brasil pelos portugueses e se espalhou por todo o território brasileiro. Devido à forma de criação solta nos terreiros das propriedades é conhecida como galinha caipira. Dela e seus ovos surgiram diversos pratos, utilizando por exemplo, estes últimos no preparo de fritadas, omeletes e doces maravilhosos, como afirmou Cascudo (1983, p. 279). Com o caldo se prepara a canja com arroz, tradicionalmente servida para os acamados, que segundo Cascudo, constitui uma superstição herdada dos escravos. Assada ou refogada pode ser servida com farinha e feijão de corda ou verde. A galinha à cabidela dos pernambucanos ou "ao molho pardo" para os baianos com tempero e sangue da galinha talhado com vinagre, também é preferência nas mesas do sertão.

Riobaldo, personagem do romance "Grande Sertão: Veredas" de Guimaraes Rosa (1963), dizia que "O sertão é do tamanho do mundo" referindo-se à porção mineira desse território. As palavras de Riobaldo representam a dimensão não só territorial mas a de um sertão com valor mítico, - revelado na culinária regional múltipla e diversificada. A variedade de iguarias, porém, vem sendo ameaçada pela nova indústria gastronômica influenciada por alimentos industrializadas ou mesmo importadas de outras regiões e do exterior.

Para entender a riqueza e diversidade das comidas do sertão, os próprios sertanejos testemunham sobre os seus ingredientes, sabores, modos de fazer e transformações. Em alguns municípios do sertão baiano, relatos de cozinheiras, feirantes, proprietários de restaurantes, senhoras idosas e visitantes, dentre outros, - que consomem esses alimentos desde a sua infância -, possibilitaram o entendimento da continuidade e diversidade, presente na culinária regional como veremos a seguir. 
A memória coletiva é relevante e permite entender a evolução e heranças predominantes e duradouras na cozinha sertaneja. Uma cozinheira da cidade de Euclides da Cunha afirmou que na sua infância muitos pratos tinham uma forte ligação com o que era oferecido pela caatinga. Aves como as rolinhas, roedores como os mocós e os preás, como confirmam, eram preparados com o leite de licuri.

Em Canudos, o depoimento de outra cozinheira proprietária de restaurante, destacou a buchada de bode como a maior lembrança dos pratos preparados por sua avó e sua mãe. $\mathrm{O}$ consumo no passado se dava somente nas residências das famílias e não em bares e restaurantes, como pode ser encontrado nos dias de hoje. Além do preparo de caças, a entrevistada afirmou que aprendeu a cozinhar com a mãe e que, hoje, poucas são as pessoas que se interessam em aprender a preparar os pratos típicos tradicionais.

Destacando a procura pela buchada, disse que só usa o fato e as tripas, diferente de preparos de outros cozinheiros que, como na cabidela utilizam o sangue do animal. O motivo principal para não utilizar o sangue está ligado às questões religiosas, especialmente como respeito à clientela evangélica, cada vez mais crescente no Brasil e, em especial a que frequenta o seu restaurante e não comem pratos com esse ingrediente.

Além dos pratos que tem o bode como componente, muitas cozinheiras comentam que herdaram dos antepassados, também, o preparo de outras comidas como a feijoada, o pirão de galinha caipira, o sarapatel de porco, caldo de aipim, entre outros. Em boa parte dos restaurantes conhecidos como regionais visitados no sertão baiano, foram encontrados outros tipos de comida, - como panquecas, lasanhas, macarronadas, purê de batata, batata frita -, o que foi justificado pelos proprietários por conta de muitas pessoas, em geral visitantes, sentirem repugnância por alguns pratos regionais.

Um dos proprietários de restaurante em Euclides da Cunha confirmou que alguns clientes realmente "ficam com nojo, principalmente os jovens acostumados a comer pratos da moda" nas cidades e capitais. A cozinheira desse restaurante declarou que sente necessidade de preservar a cultura local e que esses pratos representam isso.

Normalmente os visitantes de cidades do sertão baiano se interessam pelas comidas desses restaurantes, pois as classificam como diferentes. Muitas pessoas curiosas se interessam pelas formas de preparo de alguns pratos, valorizando a cultura até mais do que os próprios moradores locais.

Na cidade de Uauá, uma cozinheira falou que desconhecia a história dos pratos, mas reforçou informação de que as suas receitas passaram de geração em geração. Se orgulha do 
sabor de sua comida. Comentou que os moradores locais não acham nada de diferente nas suas comidas, mas que os visitantes, vindos de fora, gostam e valorizam tudo que se refere às tradições. Com a ajuda de informações de membros da sua família, outros pratos típicos são servidos nesse restaurante em Uauá, como o caldo de mocotó com aipim, o mocotó com licuri e o torresmo de porco.

O caldo de mocotó é feito com pedaços do mocotó temperados com vinagre, limão, cebola, alho, pimenta do reino, orégano, alecrim, noz moscada, folha de louro, colorau, pimentão, pimenta malagueta e sal. Cozinhado em panela de pressão por noventa minutos e misturados depois com um creme feito do aipim cozido e batido no liquidificador, o caldo é servido acompanhado de ovos de codorna.

O mocotó com licuri é preparado com sal, temperos secos e verdes, sendo refogado um pouco antes de colocar água para cozinhar. Quando está bem cozido e com um pouco de caldo, coloca o leite do licuri deixando ferver um pouco e em seguida desligar o fogo.

Consta que a cozinha sertaneja possui a maior diversidade e possibilidades de sabores. Tem-se como exemplo os pratos, nos quais os cactos como o mandacaru, o umbu, a algaroba e o licuri, entre outros produtos típicos do sertão que servem de base para os pratos desta cozinha que envolve o bioma caatinga e a cultura e costumes do povo sertanejo envolvendo as atitudes em relação ao clima, quando inventava o que comer, utilizando o que o ambiente oferecia. A gastronomia da caatinga, como é chamada, mostra a verdadeira riqueza do povo sertanejo, riqueza esta que não é valorizada e, na maioria das vezes, passa despercebida. Para criação dessa gastronomia típica, mas, recriada, são desenvolvidas diversas técnicas, que vão, desde a colheita dos ingredientes, no meio da caatinga, até o preparo e finalização dos pratos em restaurantes do sertão.

O sertanejo, assim, vem redescobrindo os cactos encontrados no ambiente em que ele vive e que podem ter mais valor além de ser apenas componente da paisagem das regiões secas. A utilização dos cactos e outros vegetais da caatinga, de modo geral, podem complementar a alimentação das pessoas como acontece com a batata doce, a macaxeira, o quiabo, a abóbora, a carne de bode, a carne seca, por exemplo. Alguns estudiosos consideram os cactos como o alimento que é capaz de mudar a realidade de milhares de nordestinos que ainda passam por problemas de desnutrição ligados à falta de alimentação sadia.

Considerando os cactos como o alimento e as novas tendências da gastronomia sertaneja, cozinheiras do sertão baiano, como em Monte Santo, vem realizando experimentos com resultados muito bons, quanto ao paladar daqueles que provam estes pratos. Segundo Radel 
(2002, p. 27) a palma forrageira, por exemplo, é possuidora de elevados teores de vitaminas e sais minerais com percentuais consideráveis de cálcio, fósforo e magnésio, sendo de boa palatabilidade e digestibilidade.

São preparados os seguintes pratos: vinagrete de palma, feita com pequenos pedaços misturados com cebola, pimentão, tomate, coentro e cebolinha. Mistura-se tudo e se acrescenta vinagre e óleo, estando pronta para servir. A palma com peixe, ao leite de licuri, é outro prato feito com o peixe frito, servido junto com a palma picada em uma panela com duas xicaras de leite de licuri, temperado com cebola, coentro, cebolinha, tomate e folha de louro, deixando cozinhar por uns dez minutos. Esse prato pode ser feito, também, com o broto de palma que é mais macio. $\mathrm{O}$ bolinho de palma com arroz é feito, se utilizando a palma picada misturada com arroz cozido e cebola, alho, tomate, coentro, cebolinha e farinha de trigo. Se faz os bolinhos e frita em óleo quente. Além dessas receitas, outras possibilidades de pratos vem sendo experimentandos, como a omelete e a farofa de palma.

As degustações, as observações, visitas e entrevistas, realizadas nos municípios de Monte Santo, Euclides da Cunha, Uauá e Canudos permitiram detectar características similares das comidas, entre si, e reconhecidas como regionais.

\section{Considerações Finais}

A história do sertão baiano apresenta características que envolvem fé e emoção dos que ali conseguiram e conseguem viver na e da caatinga. $\mathrm{O}$ clima e a vegetação aliados à seca e escassez generalizada, representam beleza e tristeza, fartura e sofrimento na cultura dessa região. Tomando como referência uma porção de território desse sertão, foi possível compreender como o clima influenciou e influencia a vida e os costumes dos lugares e seus habitantes, envolvendo os saberes populares e a cultura específica das identidades territoriais, em particular a cozinha sertaneja, considerada patrimônio cultural imaterial.

A realização desse estudo proporcionou a possibilidade de levar o tema regional do sertão baiano para além da academia, já que a cultura sertaneja a exemplo da culinária, é encontrada hoje nas grandes capitais, revelada muitas vezes equivocadamente como exótica, por ser oriunda de um lugar pobre, desconhecido e isolado.

As comidas de diversos territórios baianos estão condicionadas primordialmente às suas características climáticas. Assim, o estudo revelou os valores do sertão, verificando-se a carência de um conjunto de proposições que valorizem as particularidades culturais, em 
especial o que é produzido regionalmente como os ingredientes da culinária que com as facilidades da atualidade fazem parte dos princípios de participação comunitária e sustentabilidade das comunidades.

O estudo mostrou ainda de forma positiva que os costumes alimentares constituem por um lado um patrimônio sociocultural do sertão e por outro um marco de identificação do território do semiárido sertanejo. Nessa linha, o sertão baiano com todos os problemas associados ao clima e os preconceitos contra seu povo, apresenta uma cultura alimentar diversa e distinta das demais regiões do País.

\section{Referências}

ALMEIDA, José Américo de. A bagaceira. São Paulo: Círculo do Livro, 1980.

AMON, Denise; MALDAVSKY, David. Introdução à abordagem sócio-psicológica da comida como narrativa social: estados da arte. 2012. Disponível em: http://dspace.uces.edu.ar:8180/jspui/bitstream/123456789/1681/1/Amon_Maldavsky.pdf.

Acesso em 10 dez. 2016.

ASSIS, Ana Marlúcia Oliveira et al. Bró, caxixe e ouricuri estratégias de sobrevivência no semiárido baiano. Revista de Nutrição, Campinas/SP, v. 12, nº 2, p. 159-166, mai /ago., 1999.

CASCUDO, Luiz de Câmara. História da alimentação no Brasil. Belo Horizonte: Itatiaia, 1983, v. 1.

CORNER, Dolores Martín Rodríguez; ANGELO, Elis Regina Barbosa. O patrimônio cultural imaterial sob a perspectiva da gastronomia. SEMINÁRIO DE PESQUISA EM TURISMO DO MERCOSUL. Semintur, Anais 5, local? 2008. Disponível em http://www.ucs.br/ucs/tplPadrao/tplVSeminTur\%20/eventos/seminarios_semintur/semin_tur_ 5/trabalhos/gt13/arquivos/gt13-05.pdf. Acesso em 12 nov. 2016.

CUNHA, Euclides. Os sertões. 27ed. Brasília/DF: Universidade de Brasília, 1963.

FERNANDES, Caloca. Viagem gastronômica através do Brasil. $7^{\mathrm{a} e d . ~ S a ̃ o ~ P a u l o: ~ S E N A C, ~}$ 2000.

GARCÍA CANCLINI, Nestor. Consumidores e cidadãos: conflitos multiculturais da globalização. Tradução de Maurício Santana Dias Rio de Janeiro: UFRJ, 1995.

GUIMARÃES FILHO, Clovis; LOPES, Paulo Roberto Coelho; SILVA, Pedro Carlos Gama da. Elementos para subsidiar a formulação de um programa de convivência com a seca no semiárido brasileiro. $2003 . \quad$ Disponível em: www.irpaa.org/Elementos_para_formulacao_de_um_programa_de_convivencia_com. Acesso em 19 ago. 2016. 
MACIEL, Maria Eunice; GARCIA, Rosa Wanda Diez. Identidade cultural e alimentação. Rio de Janeiro: Fiocruz, 2005. p. 49-55. (Col. Antropologia e Saúde)

MASCARENHAS, Rubia Gisele Tramontin. A diversidade gastronômica como fator de identidade cultural nos campos gerais: potencialidades para o turismo regional. Revista Eletrônica Geografar, Resumos do VI Seminário Interno de Pós-Graduação em Geografia. Curitiba, v. 2, p.65-65, 2007.

OLIVEIRA, Trícia. A rica contribuição dos negros à cozinha brasileira, do dendê até as trocas culinárias com índios e portugueses. Brasília: 18 de novembro de 2011; Disponível em: http://www.querocomer.com.br/noticia/2011/11/a-ricacontribuicao-dos-negros-a-cozinhabrasileira-do-dende-ate-as-trocas-culinarias-comindios-e-portugueses Acesso em 4 jun. 2016.

POULAIN, Jean-Pierre et al. Sociologia da alimentação: os comedores e o espaço social alimentar. $2^{\mathrm{a}}$ ed. Florianópolis: UFSC, 2013.

QUEIROZ, Rachel de. O Quinze. 82a ed. Rio de Janeiro: José Olympio: 2006.

RADEL, Guilherme. A cozinha sertaneja da Bahia: as origens, a evolução e as receitas da cozinha sertaneja baiana. Salvador: SENAC, 2002.

RAMOS, Graciliano. Vidas secas. 102.ed. Rio de Janeiro: Record, 2007.

ROSA, João Guimarães. Grande sertão: veredas. Rio de Janeiro: José Olympio 1963.

SPIX, Johann Baptist von; MARTIUS, Carl Friedrich Philipp von. Viagem pelo Brasil: 18171820. 3ed. São Paulo: Melhoramentos. 1976. v. 2.

SUASSUNA, Ana Rita Dantas. Gastronomia sertaneja: receitas que contam histórias. São Paulo: Melhoramentos, 2010.

TEMPASS, Mártin César. Orerémbiú: a relação das práticas alimentares e seus significados com a identidade étnica e a cosmologia Mbyá-Guarani. 2005. 156 fl. Dissertação (Mestrado em Antropologia Social), Programa de Pós-Graduação em Antropologia Social da Universidade Federal do Rio Grande do Sul -PPGAS/UFRGS. Porto Alegre, 2005. 